\title{
Thermal degradation kinetics of polybutadiene rubber
}

\author{
Jyh-Ping Lin, ${ }^{a}$ Ching-Yuan Chang, ${ }^{a *}$ Chao-Hsiung $\mathrm{Wu}^{b} \&$ Shin-Min Shih ${ }^{c}$ \\ ${ }^{a}$ Graduate Institute of Environmental Engineering, National Taiwan University, Taipei 106, Taiwan, China \\ ${ }^{b}$ Department of Environmental Engineering, Da-Yeh Institute of Technology, Chang-Hwa 515, Taiwan, China \\ 'Department of Chemical Engineering, National Taiwan University, Taipei 106, Taiwan, China
}

(Received 5 February 1996; accepted 7 March 1996)

\begin{abstract}
The thermal degradation kinetics of polybutadiene rubber (BR) was investigated by dynamic thermogravimetry, in a nitrogen atmosphere, over the temperature range $177-577^{\circ} \mathrm{C}$ and at constant nominal heating rates of 3,5 and $7^{\circ} \mathrm{C} / \mathrm{min}$, respectively. Two distinct mass change stages in the thermogravimetric analysis (TGA) curves indicated that the degradation of BR may be attributed to two reactions. The corresponding activation energies, frequency factors and reaction orders of the two reactions were determined. A simplified two-reaction model based on the TGA curves was also proposed for engineering purposes. Satisfactory agreements between the proposed model and the experimental results were obtained. The results of this study are useful for the utilization of scrap BR as an alternative energy resource. (C) 1996 Elsevier Science Limited
\end{abstract}

\section{INTRODUCTION}

In Taiwan, polybutadiene rubber $(\mathrm{BR})$ is classified as one of the principal manufacturing products of the synthetic rubber industry. Production quantities of BR have increased from about 35000 metric tons in 1986 to about 43000 metric tons in $1993 .{ }^{1}$ About 78000 metric tons of used tyres were discarded in 1991, while the amount was estimated to be 58000 metric tons in $1989 .{ }^{2}$ The growth ratc of scrap tyres is high. Therefore, the treatment and disposal of rubber wastes has become a problem because of concern for the environment and care of the globe. Some studies and review literature indicate that proper pyrolysis methods may be appropriate solutions for both problems of treatment and minimization of rubber waste or scrap tyres. ${ }^{3-11}$ Scrap tyres contain a vast amount of synthetic rubber with extremely high calorific value, say $40000 \mathrm{~kJ} / \mathrm{kg}$. Because of the high calorific value, the conversion of scrap tyre or rubber wastes to

* To whom all correcpondence should be addressed. market-ready products has become a principal focus from both the economical and environmental standpoints.

Several types of pyrolysis processes, such as fluidized bed processes, ${ }^{12-14}$ batch processes, ${ }^{15-19}$ vacuum processes, ${ }^{20}$ molten salt processes, ${ }^{21-23}$ and coprocessing with heavy oil, ${ }^{7,24}$ have been tried for the treatment of rubber wastes, scrap tyres and automobile shredder wastes. The gas products may contain hydrogen, methane, ethane, propylene, butene, butadiene, etc., while benzene, toluene, xylene, ethylbenzene, limonene, naphthalene, etc. are identified in the oil products. ${ }^{13,14,19}$ The conversion of pyrolysis residues into activated carbon may be one of the most effective usages of chars obtained through pyrolysis of rubber wastes, and the desired characteristics of final solid products could also be obtained..$^{18,25,26}$

Methods for the treatment of mass-loss curves, obtained through thermogravimetric analysis (TGA), have previously been studied and reviewed. ${ }^{27-29}$ The thermal degradation of polybutadiene with an apparent activation energy of 
$251 \mathrm{~kJ} / \mathrm{mol}$ and maximum degradation rate of $0.0091 \mathrm{~min}^{-1}\left(375^{\circ} \mathrm{C}\right)$ has been performed by the use of derivative thermogravimetric analysis (DTG). ${ }^{30}$ The decomposition of polybutadiene, studied by pyrolysis gas chromatography (PGC), is mainly by bond scission followed by unzipping to yield butadiene monomer at lower temperatures, while at higher temperatures the $\mathrm{H}$ transfer reaction is followed resulting in the formation of one saturated end and the other unsaturated. ${ }^{31}$ A dynamic thermogravimetry study indicated that the pyrolysis of used tyres in the temperature range of $417-457^{\circ} \mathrm{C}$ follows first-order kinetics with an activation energy of $170 \mathrm{~kJ} / \mathrm{mol}^{32}$ The activation energies for the pyrolysis of $\mathrm{BR}$ and styrene-butadiene rubber (SBR) were reported to be 263.4 and $253.6 \mathrm{~kJ} / \mathrm{mol}$ with maximum degradation rate occurring at 473 and $460^{\circ} \mathrm{C}$, respectively, but the pyrolysis schemes were not mentioned any further. ${ }^{33}$ The pyrolysis of waste tyres, in the temperature range from 300 to $900^{\circ} \mathrm{C}$, has been investigated by isothermal $\mathrm{TG}$, and the activation energy was determined to be $613.0 \mathrm{~kJ} / \mathrm{mol}$ with the second-order reaction. ${ }^{34}$ For the temperature range $175-450^{\circ} \mathrm{C}$, the activation energies for the pyrolysis of $\mathrm{BR}$ in an oxidative atmosphere were estimated to be 66.8 (175$\left.275^{\circ} \mathrm{C}\right), 86.1 \quad\left(275-350^{\circ} \mathrm{C}\right)$ and $209.4 \quad(350-$ $\left.450^{\circ} \mathrm{C}\right) \mathrm{kJ} / \mathrm{mol}^{35}$ In the temperature range $300-500^{\circ} \mathrm{C}$, a first-order reaction could be adequately used to describe the pyrolysis kinetics of BR with activation energy $215 \mathrm{~kJ} / \mathrm{mol}$ and frequency factor $6.32 \times 10^{14} \mathrm{~min}^{-1} \cdot{ }^{36}$ Also, no reaction scheme was suggested. Therefore, there is a need to propose a convenient method to determine the reaction rate for the pyrolysis of $\mathrm{BR}$ and to suggest a simplified reaction model which may properly describe the pyrolysis history of BR.

It is thus the aim of the present work to deal with the degradation of $B R$ to provide a simple reaction model for enginecring purposes. The pyrolyzer was a dynamic thermogravimetry system at the temperatureprogrammed constant heating rates of 3,5 and $7^{\circ} \mathrm{C} / \mathrm{min}$, respectively, in a nitrogen atmosphere. The corresponding activation energies, frequency factors and orders of reactions were determined. A simple reaction model is proposed for describing the pyrolysis of BR. All these results are useful for the pyrolytic treatment of rubber wastes of BR.

\section{EXPERIMENTAL}

\subsection{Materials}

A commercial-grade BR was used in this study. It was supplied by the Taiwan Synthetic Rubber Corporation. Property, elemental and calorific value analyses of the samples are listed in Table 1. Nitrogen gas, with $99.99 \%$ purity, was purchased from the Ching-Feng-Harng Co. Ltd in Taipei, Taiwan.

\subsection{Apparatus and procedures}

The experimental flow diagram for the pyrolysis of BR is shown in Fig. 1. Details of the experimental methods have been described in detail previously. ${ }^{37}$

\section{RESULTS AND DISCUSSION}

\subsection{Effects of temperature and heating rate}

The residual mass fraction of active reactant $(M)$ is expressed on a normalized basis, $M=(W-$ $\left.W_{\mathrm{f}}\right) /\left(W_{\mathrm{o}}-W_{\mathrm{f}}\right)$, where $W, W_{\mathrm{o}}, W_{\mathrm{f}}=$ mass, initial mass and final mass of the sample, respectively. The variation of $M$ with reaction temperature $(T)$ is shown in Fig. 2. There are two principal reactions as distinguished by the two distinct mass changes in Fig. 2 over the experimental

Table 1. Some properties of BR used in this study

\begin{tabular}{lc}
\multicolumn{1}{c}{ Item } & Property \\
\hline Trade name & TAIPOL BR 0150 \\
Configuration & $96 \%^{a}$ Cis minimum \\
Elemental analysis (weight $\%)$ & \\
C & $88.72(0.005)^{b}$ \\
H & $11.17(0.01)$ \\
O & $\mathrm{ND}^{c}$ \\
S & $<0.1$ \\
Cl & $2.04(0.01)$ \\
Composition analysis $(w t \%)$ & $0.36(0.01)$ \\
Moisture & \\
Ash & $0.22(0.0037)$ \\
Combustible & $0.08(0.0030)$ \\
Calorific value $(\mathrm{kJ} / \mathrm{kg})$ & $99.70^{d}$ \\
\hline
\end{tabular}

\footnotetext{
"In weight percent.

${ }^{b}$ Numbers in parentheses are standard deviations.

${ }^{c}$ Not detected.

${ }^{d}$ Combustible $=1-$ moisture - ash .
} 


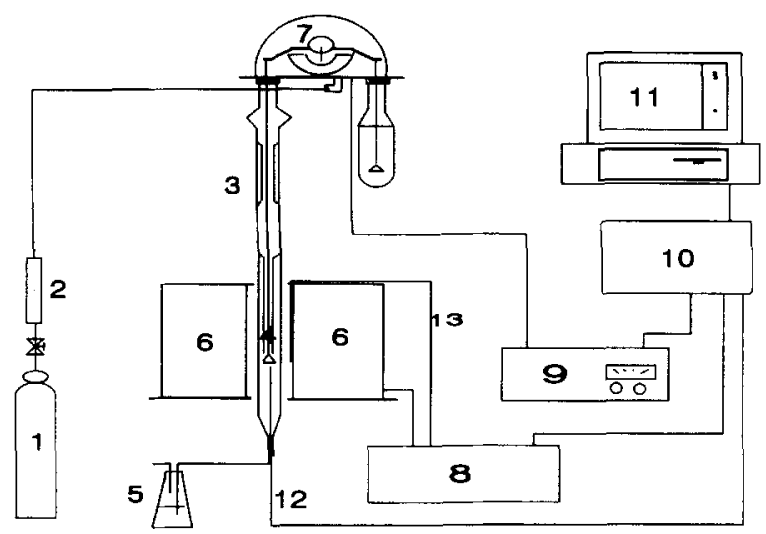

Fig. 1. Schematic diagram of apparatus for the pyrolysis of BR. 1: Nitrogen; 2: flow meter with needle valve; 3 : reactor; 4: extension wire and sample disk; 5: trap; 6: furnace; 7: electrobalance; 8: temperature controller; 9: electrobalance controller; 10: data acquisition unit; 11: personal computer; 12, 13: K-type thermocouples.

range for the three different heating rates $(\beta)$ under investigation. At a temperature of about $227^{\circ} \mathrm{C}(500 \mathrm{~K})$, the first reaction of mass change begins and goes on up to about $427^{\circ} \mathrm{C}(700 \mathrm{~K})$ with $M=0.805$, which may also be judged by the use of plots of $\mathrm{d} X / \mathrm{d} t$ and $\mathrm{d}^{2} X / \mathrm{d} t^{2}$ versus $T$ ( $X=1-M, t=$ reaction time). Afterwards, the second reaction proceeds and goes on to the end. The first reaction may be attributed to the thermal formation of volatiles $V_{1}$, which are much easier to form at lower temperatures and with a slower reaction rate. The second reaction, which is a reaction with a faster rate, may be the degradation of intermediates yielding volatiles $\mathrm{V}_{2}$.

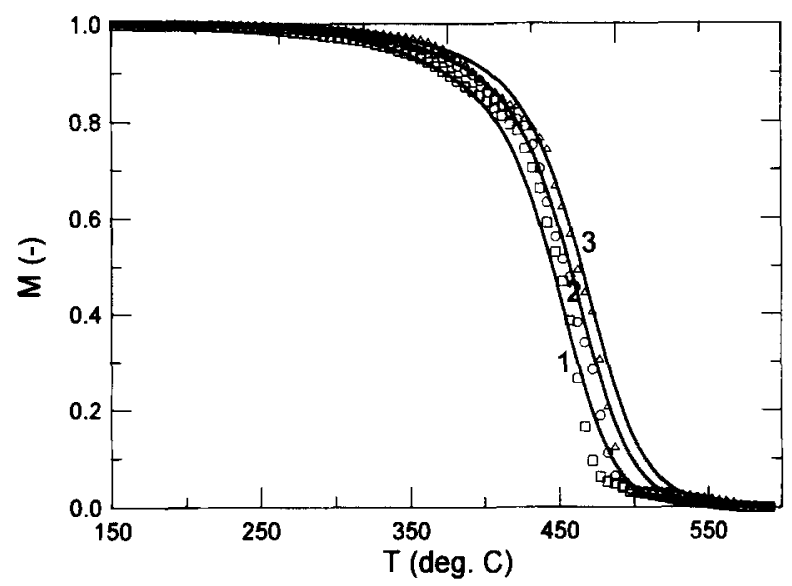

Fig. 2. Comparison of residual mass fraction $(M)$ by model prediction with experimental data at different heating rates $(\beta)$ for pyrolysis of BR. $\square$ and $1, O$ and 2 , and $\Delta$ and 3 : experimental and predicted results for $\beta=3,5$ and $7^{\circ} \mathrm{C} / \mathrm{min}$.

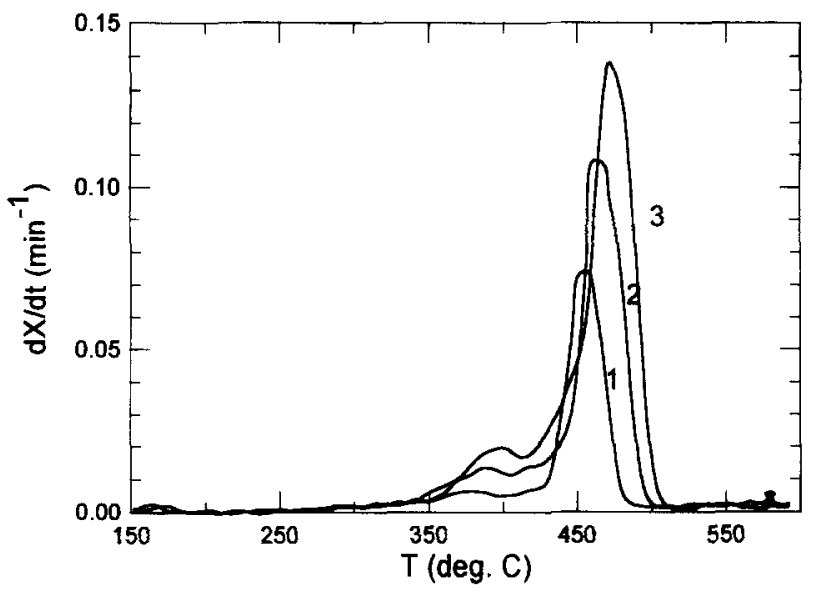

Fig. 3. Variations of instantaneous reaction rates $(\mathrm{d} X / \mathrm{d} t)$ with temperature $(T)$ for pyrolysis of $\mathrm{BR}$ at various heating rates $(\beta) .1,2,3: \beta=3,5,7^{\circ} \mathrm{C} / \mathrm{min}$.

The variations of instantaneous reaction rates $(r=\mathrm{d} X / \mathrm{d} t)$ with temperature $(T)$ under the three heating rates are shown in Fig. 3. It is noted that two peak rates can be identified from the rate curves. For instance, the first peak occurs at about $387^{\circ} \mathrm{C}(660 \mathrm{~K})$ with a reaction rate of about $0.021 \mathrm{~min}^{-1}$ for a heating rate of $7^{\circ} \mathrm{C} / \mathrm{min}$; the second is around $467^{\circ} \mathrm{C}(740 \mathrm{~K})$ with a reaction rate of $0.147 \mathrm{~min}^{-1}$ under the same heating rate. This may suggest that two major reactions proceed throughout the experimental conditions. The corresponding fractions $F_{1}$ and $F_{2}$ caused by the first and second reactions are determined to be $0.195(=1-0.805)$ and 0.805 , respectively.

\subsection{Kinetic parameters}

The foundation for the study of kinetic data from the mass-loss curve is based on the basic rate equation:

$$
r=\mathrm{d} X / \mathrm{d} t=k f(X)
$$

where

$$
\begin{gathered}
k=\text { the Arrhenius rate constant, } \\
k=A \exp (-E / \mathrm{R} T),
\end{gathered}
$$

$A, E=$ frequency factor, activation energy,

$\mathrm{R}, n=$ universal gas constant, reaction order,

$f(X)=$ the function of conversion $X, f(X)=$ $(1-X)^{n}$.

The differential, iso-conversion method for determining the activation energy was employed in this study. The activation energies at various conversions are shown in Fig. 4. The results indicate that values of the activation energy for 


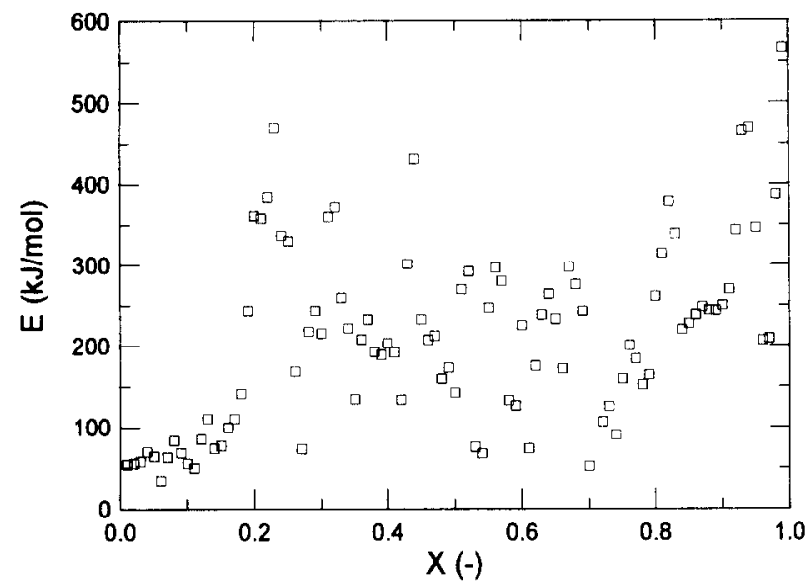

Fig. 4. Variations of activation energies $(E)$ with conversion $(X)$ for pyrolysis of BR.

the pyrolysis of BR are about $50-500 \mathrm{~kJ} / \mathrm{mol}$. According to the results shown in Figs 2 and 3, two reactions are observed. The arithmetic means of the activation energies corresponding to the two reactions are $59.8 \mathrm{~kJ} / \mathrm{mol}$ for the first reaction $(X: 0.02-0.11)$ and $197.0 \mathrm{~kJ} / \mathrm{mol}$ for the second reaction $(X: 0.40-0.80)$, respectively. Some kinetic parameters of scrap tyres or rubber wastes are listed in Table 2 indicating that the activation energies are in the range of about $50-600 \mathrm{~kJ} / \mathrm{mol}$. The reaction order $(n)$ can be obtained from the slope of the plot of $\ln [(\mathrm{d} X / \mathrm{d} t) / \exp (-E /(\mathrm{R} T))]$ versus $\ln (1-X)$ for each reaction as shown in Fig. 5. Therefore, the reaction orders of the two different reactions are

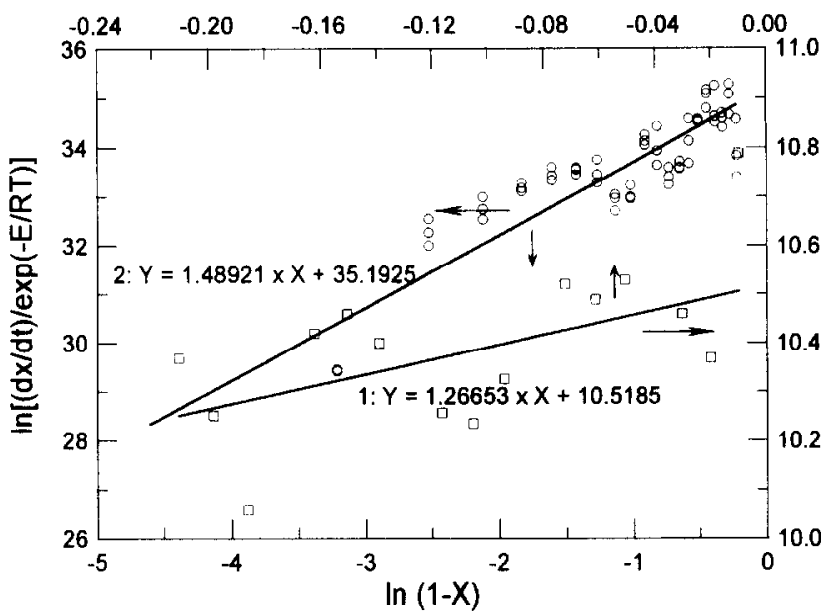

Fig. 5. Variations of $\ln [(\mathrm{d} X / \mathrm{d} t) / \exp (-E /(\mathrm{R} T))]$ with $\ln (1-X)$ for determination of reaction order and frequency factor for pyrolysis of BR. $\square$ and 1 , and $O$ and 2: experimental and correlated results of first and second reactions.

$1.27(E=59.8 \mathrm{~kJ} / \mathrm{mol})$ and $1.49 \quad(E=$ $197.0 \mathrm{~kJ} / \mathrm{mol}$ ) for the first and second reactions, respectively. The frequency factors are determined by the use of temperature dependence of reaction rate constant, i.e. the Arrhenius law as shown in Fig. 6, which shows $\ln k$ versus $1 / T$ with the slope of $-E / R$ and the intercept of $\ln A$. Thus, the values of frequency factors are $2.8 \times 10^{3}$ and $1.9 \times 10^{13} \mathrm{~min}^{-1}$ for the first and second reactions, respectively. Values of $E, A, n$ and $F$ for the two reactions of BR pyrolysis are listed in Table 3.

Table 2. Comparison of kinetic parameters of pyrolysis of scrap tyres or rubber wastes

\begin{tabular}{|c|c|c|c|c|c|}
\hline Material used & Test method & $\begin{array}{l}\text { Activation energy } \\
(\mathrm{kJ} / \mathrm{mol})\end{array}$ & $\begin{array}{l}\text { Max. reaction } \\
\text { rate }\left(\min ^{-1}\right)\end{array}$ & $\begin{array}{l}\text { Reaction } \\
\text { order }\end{array}$ & $\begin{array}{l}\text { Frequency factor } \\
\qquad\left(\min ^{-1}\right)\end{array}$ \\
\hline Polybutadiene $^{30}$ & Derivative TG & 251 & $0.0091\left(375^{\circ} \mathrm{C}\right)^{a}$ & - & - \\
\hline Tyre waste ${ }^{15}$ & Batch process & 125.5 & - & 1 & $1.1 \times 10^{9}$ \\
\hline Used tyre 32 & Dynamic TG & 170.0 & - & 1 & - \\
\hline $\mathrm{BR}^{33}$ & Dynamic TG & 263.4 & $-\left(473^{\circ} \mathrm{C}\right)$ & - & - \\
\hline $\mathrm{SBR}^{33}$ & Dynamic TG & 253.6 & $-\left(460^{\circ} \mathrm{C}\right)$ & - & - \\
\hline Waste tyre ${ }^{34}$ & Isothermal TG & 613.0 & - & 2 & $3.3 \times 10^{5}$ \\
\hline $\mathrm{BR}^{35}$ & Dynamic TG & $66.8 ; 86.1 ; 209.4^{b}$ & - & - & $\begin{array}{l}7.2 \times 10^{7} ; 4.9 \times 10^{6} \\
1.4 \times 10^{15}\end{array}$ \\
\hline $\mathrm{SBR}^{35}$ & Dynamic TG & $112 ; 126.9 ; 331.1 ; 160.7^{c}$ & - & - & $\begin{array}{l}3.7 \times 10^{12} ; 9.5 \times 10^{9} \\
7.9 \times 10^{23} ; 2.5 \times 10^{10}\end{array}$ \\
\hline $\mathrm{BR}^{36}$ & Derivative TG & 215 & - & 1 & $6.32 \times 10^{14}$ \\
\hline $\mathrm{SBR}^{36}$ & Derivative TG & 152 & - & 1 & $1.78 \times 10^{10}$ \\
\hline \multirow[t]{2}{*}{$\mathrm{BR}^{d}$} & Dynamic TG & 59.8 & $0.021\left(387^{\circ} \mathrm{C}\right)^{e}$ & 1.27 & $2.8 \times 10^{3}$ \\
\hline & & 197.0 & $0.147\left(467^{\circ} \mathrm{C}\right)$ & 1.49 & $1.9 \times 10^{13}$ \\
\hline
\end{tabular}

\footnotetext{
${ }^{a}$ Numbers in parentheses are temperatures at which max. reaction rates occur.

${ }^{b}$ Temperature ranges: $175-275^{\circ} \mathrm{C}$ for $66.8,275-350^{\circ} \mathrm{C}$ for 86.1 , and $350-450^{\circ} \mathrm{C}$ for 209.4 ; under oxidative atmosphere.

${ }^{c}$ Temperature ranges: $175-275^{\circ} \mathrm{C}$ for $112,275-350^{\circ} \mathrm{C}$ for $126.9,350-450^{\circ} \mathrm{C}$ for 331.1 , and above $450^{\circ} \mathrm{C}$ for 160.7 ; under oxidative atmosphere.

${ }^{d}$ This study.

${ }^{e}$ Data for heating rate of $7^{\circ} \mathrm{C} / \mathrm{min}$.
} 


\subsection{Kinetic model}

According to the kinetic parameters obtained above and the temperature dependence of reaction rates (Fig. 6), there exist two reactions which may proceed for the pyrolysis of BR in this study. Thus, a reaction model based on the residual curves is proposed to represent the pyrolysis of BR as follows:
Table 3. Values of $E, A, n$ and $F$ for two reactions of $B R$ pyrolysis in this study

\begin{tabular}{lcc}
\hline & First reaction & Second reaction \\
\hline$E(\mathrm{~kJ} / \mathrm{mol})$ & 59.8 & 197.0 \\
$A\left(\mathrm{~min}^{-1}\right)$ & $2.8 \times 10^{3}$ & $1.9 \times 10^{13}$ \\
$n$ & 1.27 & 1.49 \\
$F$ & 0.195 & 0.805 \\
\hline
\end{tabular}

$F$ : fraction contributed by each reaction.

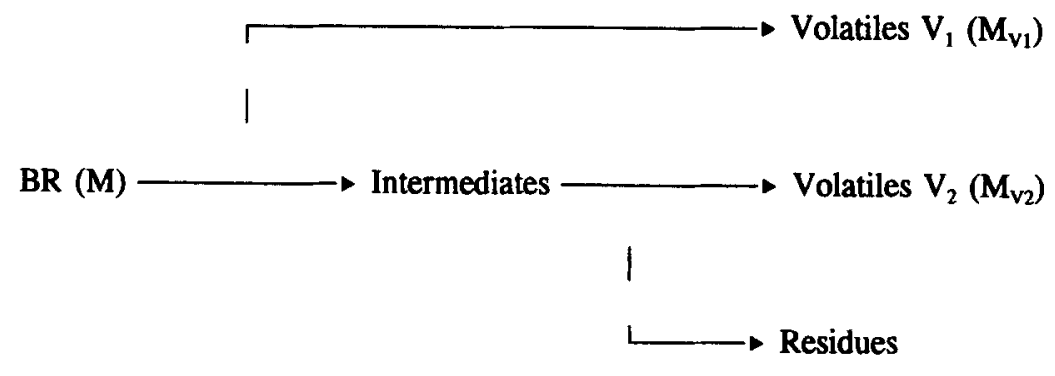

where $\mathrm{V}_{1}$ and $\mathrm{V}_{2}$ are the volatiles (with mass fractions of $M_{\mathrm{V} 1}$ and $M_{\mathrm{V} 2}$, respectively) obtained from the pyrolysis of BR and its intermediates, respectively. It can be shown that

$$
\begin{aligned}
\frac{M_{\mathrm{V} i}}{F_{i}}=1-\left[1-\left(1-n_{i}\right) \frac{A_{i} \mathrm{R} T^{2}}{\beta E_{i}}\right. & \\
& \left.\exp \left(-\frac{E_{i}}{\mathrm{R} T}\right) \sum\left(E_{i}, T\right)\right]^{1 / 1-n_{i}}
\end{aligned}
$$

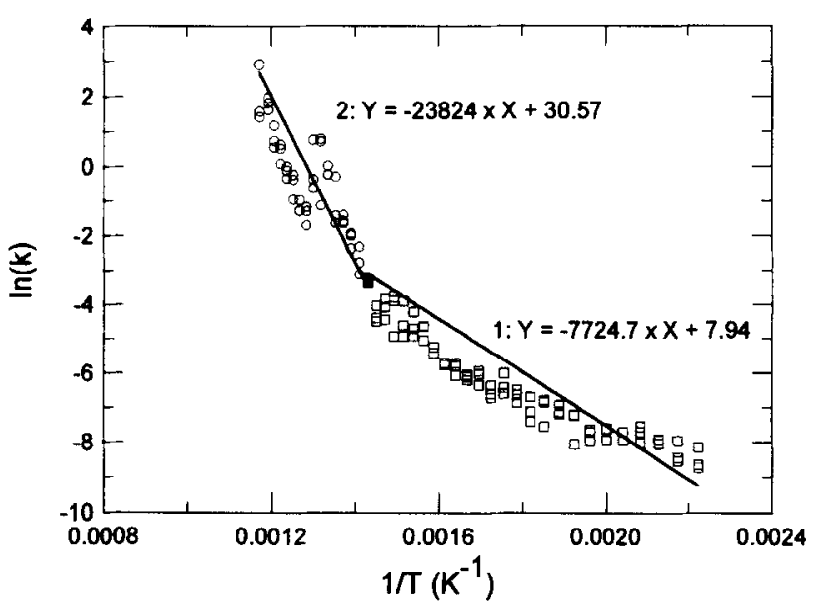

Fig. 6. Temperature dependence of the reaction rate constant $(k)$ for Arrhenius' law. $\square$ and $1, O$ and 2 : experimental data and correlated results of first and sccond reactions. where

$$
\begin{aligned}
\sum\left(E_{i}, T\right)= & \sum_{j=0}^{\infty}\left[\left(-\frac{\mathrm{R} T}{E_{i}}\right)^{j} \prod_{k=0}^{j}(k+1)\right] \\
= & 1-2 \frac{\mathrm{R} T}{E_{i}}+6\left(\frac{\mathrm{R} T}{E_{i}}\right)^{2}-24\left(\frac{\mathrm{R} T}{E_{j}}\right)^{3} \\
& +120\left(\frac{\mathrm{R} T}{E_{i}}\right)^{4}-\ldots
\end{aligned}
$$

$F_{1}$ and $F_{2}$ are 0.195 and 0.805 , respectively, as previously determined. The variations of $M_{\mathrm{v} 1}$ and $M_{\mathrm{V} 2}$ against $T$ at $5^{\circ} \mathrm{C} / \mathrm{min}$ heating rate are shown in Fig. 7. The accumulated release of $V_{1}$ increases

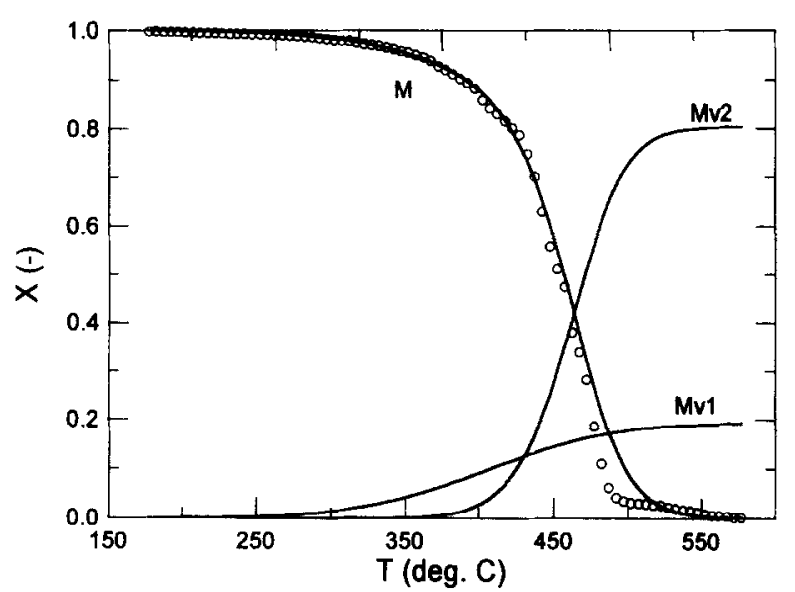

Fig. 7. Comparison of experimental data $(O)$ and predicted values $(\bullet)$ of residue mass fraction $(M)$, and computed values $(\bullet)$ of mass fractions of $\mathrm{V}_{1}\left(M_{\mathrm{V} 1}\right)$ and $\mathrm{V}_{2}\left(M_{\mathrm{V} 2}\right)$ for pyrolysis of $\mathrm{BR}$ at $\beta=5^{\circ} \mathrm{C} / \mathrm{min}$. 
steadily from about 277 to $487^{\circ} \mathrm{C}$, whereas that of $\mathrm{V}_{2}$ exhibits a rapid increase from about 377 to $507^{\circ} \mathrm{C}$. Thus, the variation trends of $M_{\mathrm{V} 1}$ and $M_{\mathrm{V} 2}$ justify the two distinct mass changes of $M$ in Fig. 2. A comparison of residual mass fractions predicted by the proposed model and those obtained by experiments is also shown in Fig. 2, indicating satisfactory agreements.

To verify the applicability of kinetic parameters and the validity of the proposed model, the coefficients of determination $\left(R^{2}\right)$ are examined for $0.05<M$ (predicted) $<0.95$, and the values of $R^{2}$ are $0.981,0.997$ and 0.994 for the heating rates of 3,5 and $7^{\circ} \mathrm{C} / \mathrm{min}$, respectively. This thus shows the validity and practical applicability of the proposed two-reaction model for describing the pyrolysis of BR without specifying the detailed chemical reactions involved.

\section{CONCLUSIONS}

Thermal degradation experiments on BR were carried out by a dynamic TG reaction system, in nitrogen atmosphere, over the temperature range $177-577^{\circ} \mathrm{C}$ and at pre-set heating rates. A simplified two-reaction model was proposed to model the experimental results. The activation encrgies, frequency factors and reaction orders were determined for the two reactions under experimental conditions. The pyrolysis of BR can be adequately described by the proposed model. This study greatly assists the reutilization of scrap $\mathrm{BR}$ as an energy resource.

\section{ACKNOWLEDGEMENTS}

We express our sincere thanks to the National Science Council of R.O.C. Taiwan for their financial support, under contract number NSC830410-E-002-022, and we would also like to thank the Taiwan Synthetic Rubber Corporation for providing the rubber sample.

\section{REFERENCES}

1. DOS/MOEA (Department of Statistics/Ministry of Economic Affair), Industrial Production Statistics Monthly Taiwan Area, The Republic of China on Taiwan, 302 (1994) 127.

2. Yang, G. C. C., Resourc. Conserv. Recycl., 9 (1993) 191.

3. Crane, G. \& Kay, E. L., Rubber Chem. Technol., 48 (1975) 50.

4. Poller, R. C., J. Chem. Technol. Biotechnol., 30 (1980) 152.

5. Dodds, J., Domenico, W. F., Evans, D. R., Fish, L. W., Lassahn, P. L. \& Toth, W. J., Scrap Tyres: A Resource and Technology Evaluation of Tire Pyrolysis and Other
Selected Alternate Technologies, DE-AC07-761DO1570, Idaho Falls, Nov. 1983.

6. Wilkins, E. S. \& Wilkins, M. G., J. Environ. Sci. Health, A20 (1985) 149.

7. Bouvier, J. M. \& Gelus, M., Resourc. Conserv., 12 (1986) 77.

8. Buekens, A. G. \& Schoeters, J. G., Conserv. Recycl., 9 (1986) 253.

9. Cypres, R. \& Bettens, B., In Pyrolysis and Gasification, eds G. L. Ferrero, K. Maniatis, A. Buekens \& A. V. Bridgwater. Elsevier, New York, 1989, p. 209.

10. Budrugeac, P. \& Ciutacu, S., Polym. Degrad. Stab., 33 (1991) 377.

11. Kaminsky, W., Makromol. Chem. Macromol. Symp., 57 (1992) 145.

12. Araki, T., Niikawa, K., Hosoda, H., Nishizaki, H., Mitsui, S., Endoh, K. \& Yoshida, K., Conserv. Recycl., 3 (1979) 155.

13. Kaminsky, W. \& Rössler, H., CHEMTECH, 22 (1992) 108.

14. Wey, M. Y., Liou, B. H., Wu, S. Y. \& Zhang, C. H., J. Air and Waste Manage. Assoc., 45 (1995) 855.

15. Bouvier, J. M., Charbel, F. \& Gelus, M., Resourc. Conserv., 15 (1987) 205.

16. Ogasawara, S., Kuroda, M. \& Wakao, N., Ind. Engng Chem. Res., 26 (1987) 2552.

17. Barbooti, M. M., Hassan, E. B. \& Issa, N. A., J. Pet. Res., 8 (1989) 229.

18. Merchant, A. A. \& Petrich, M. A., AIChE J., 39 (1993) 1370 .

19. Williams, P. T., Besler, S. \& Taylor, D. T., Proc. Inst. Mech. Engrs, Part A: J. Power and Energy, 207 (1993) 55.

20. Roy, C., Labrecque, B. \& De Caumia, B., Resourc. Conserv. Recycl., 4 (1990) 203.

21. Larsen, J. W. \& Chang, B., Rubber Chem. Technol., 49 (1976) 1120.

22. Chamber, C., Larsen, J. W., Li, W. \& Wiesen, B., Ind. Engng Chem. Process Des. Dev., 23 (1984) 648.

23. Bertolini, G. E. \& Fontaine, J., Conserv. Recycl., 11 (1987) 331.

24. Bouvier, J. M., Farhadi, F. \& Gelus, M., Int. Chem. Engng, 23 (1983) 645.

25. Boukadir, D., David, J. C., Granger, R. \& Vergnaud, J. M., J. Anal. Appl. Pyrolysis, 3 (1981) 83.

26. Giavarini, C., Fuel, 64 (1985) 1331.

27. Nishizaki, H., Yoshida, K. \& Wang, J. H., J. Appl. Polym. Sci., 25 (1980) 2869.

28. Wendlandt, W. W., Thermal Analysis. John Wiley and Sons Inc., New York, 1986.

29. Petrović, Z. S. \& Zavargo, Z. Z., J. Appl. Polym. Sci., 32 (1986) 4353.

30. Brazier, D. W. \& Schwartz, N. V., J. Appl. Polym. Sci., 22 (1978) 113.

31. Radhakrishnan, T. S. \& Rao, M. R., J. Polym. Sci., Polym. Chem. Ed., 19 (1981) 3197.

32. Funazukuri, T., Takunashi, T. \& Wakao, N., J Chem. Engng Jpn., 20 (1987) 23.

33. Kleps, T., Jaroszynska, D. \& Piaskiewicz, M., J. Therm. Anal., 36 (1990) 2257.

34. Chang, Y. M., Study on Degradation Rate of Waste Tyre during Pyrolysis Treatment, NSC82-0113-E-027-023-T, National Science Council of R.O.C. on Taiwan, Taipei, 1993 (in Chinese).

35. Kopsch, H., Plaste Kautsch, 41 (1994) 172.

36. Yang, J., Tanguy, P. A. \& Roy, C., AIChE J., 41 (1995) 1500.

37. Lin, J. P., Chang, C. Y. \& Wu, C. H., J. Chem. Technol. Biotechnol. (in press). 